
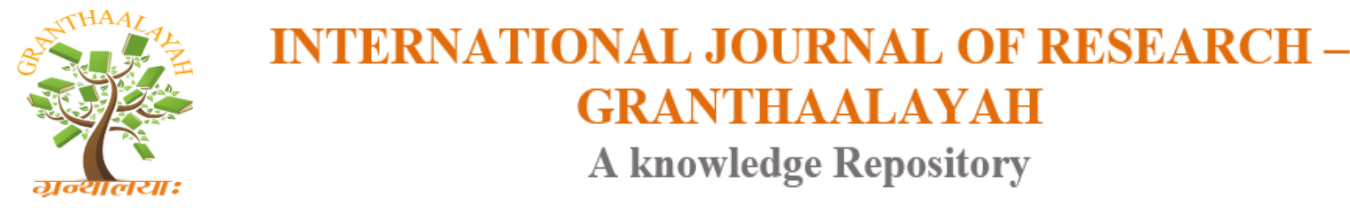

Science

\title{
ANALYSIS OF PROPERTIES OF CONCRETE USING SAFETY MATCHES POWDER AS ADMIXTURE
}

\author{
Vishal Gadgihalli ${ }^{* 1}$, MeenaY.R ${ }^{2}$, Bharath A.L ${ }^{2}$, Raghavendra Prasad HavanjeDinakar ${ }^{3}$ \\ ${ }^{* 1}$ UG Student, Department of civil engineering, Jain University, Bangalore, India \\ ${ }^{2}$ Assistant Professor, Department of civil engineering, Jain University, Bangalore, India \\ ${ }^{3}$ Research Assistant, Department of civil engineering, Jain University, Bangalore, India
}

\begin{abstract}
Recently admixtures had made a major importance in the concrete manufacturing. These admixtures materials ranged from blood in the history to the recent retarding agents. In this paper analysis of properties of concrete using safety matches powder as admixture is studied and verified the strength of concrete and temperature emitted due to chemical reaction to the normal Portland cement. Using safety matches powder the temperature emitted due to exothermal reaction of concrete has reduced. This gives better results hence we can use this safety matches powder as an admixture where the reacting temperature and the emitting temperature place a crucial role in construction and maintenance.
\end{abstract}

Keywords: Safety Matches Powder; Temperature Retardant; Admixture; Concrete Exothermal Reaction.

Cite This Article: Vishal Gadgihalli, MeenaY.R, and Bharath A.L, and Raghavendra Prasad HavanjeDinakar. (2017). "ANALYSIS OF PROPERTIES OF CONCRETE USING SAFETY MATCHES POWDER AS ADMIXTURE.” International Journal of Research - Granthaalayah, 5(11), 53-56. https://doi.org/10.29121/granthaalayah.v5.i11.2017.2327.

\section{Introduction}

A material other than water, aggregates, or cement that is used as an ingredient of concrete or mortar to control setting and early hardening, workability or to provide additional cementing properties. Over decades' attempts have been made to obtain concrete with certain desired categorists such as high compressive strength, high workability, and high performance and durability parameters to meet the requirements of complexity of modern structures. The properties commonly modified are the heat hydration, excel rate or retard setting time, workability, water reduction, dispersion and air entertainment impermeability and duration factors. Generally, admixtures are subdivided into two parts chemical admixtures and mineral admixtures. Chemical admixtures are artificial admixtures which were created by humans. Whereas, mineral admixtures, are admixtures obtained as a waste material while processing natural minerals. In the present work we consider the safety matches powder as a chemical 
admixture [5] [6]. The safety matches powder consists of mixture of red phosphorous, potassium chloride, Sulphur, sugar, rubber, glass capsules sulphuric acid, potassium chlorate, oxidizing agents, with neutralizer ( $\mathrm{Zn}$ or $\left.\mathrm{CaCO}_{3}\right), 20-30 \%$ of siliceous filler, diatomite, and glue. Recently fire retarded chemicals such as alum, sodium silicate and other salts [1] [2] and others are included in safety match powder to prevent the accidental burns.

Safety matches powder used as a chemical admixture the absorbing temperature properties and transmitting temperatures of concrete has reduced. Since, very less number of literature found related to the present study, the author just compared his work with general ordinary Portland cement.

\section{Methodology}

The matchbox powder collected from manufactures. This powder must not be exposed to sun light and other chemical reaction. Instead packing powder in aluminum sheets or polythene cover helps in protecting powder from atmospheric moisture. While mixing the powder must be free from lumps.

Target strength of concrete was determined by following equation

Target strength $=\mathrm{f}^{\prime} \mathrm{ck}=\mathrm{fck}+1.65(\mathrm{~s})$ from IS10262-2009 [3]. The amount of hair admixture was calculated from the following equation,

Volume of powder used $=$ (mass of chemical admixture/specific gravity of admixture *1000) [4] The specific gravity of safety matches was found 1.82 by Le-Chatelier princlpe [5]

[6]. The cube casted for the size $15 \mathrm{~cm} 3$. The compression and flexure strength were tested for 1 , $3,7,21,23,28$ days after casting.

An empty spaced cube with bottom, size of $10 * 10 * 10 \mathrm{~cm}$ casted using concrete with safety matches powder concrete and walls of thickness $1 \mathrm{~cm}$. Water of $1000 \mathrm{c}$ was filled in empty cube and the time consumed for reduction of temperature of water to $400 \mathrm{c}$ were noted down. This gives the time consumed by cube to reduce inner temperature of $1000 \mathrm{c}$ of water to 400c. An empty cube casted by using safety matches powder concrete size $10 * 10 * 10$ was inserted into another larger empty cube casted using plane cement concrete size of $15^{*} 15^{*} 10 \mathrm{~cm}$. $3 \mathrm{~cm}$ sufficient space was left between two cubes was filled with Water of 100c and top side of cube was closed by lid. Water temperature was noted down after 8 mins for 1,3,7,21,23 and 28 days of similar casted samples. The difference between the water temperature noted after $8 \mathrm{~min}$ and the temperature at room temperature gives the amount of heat transmitted through the walls of inner cube. 


\section{Results and Discussions}
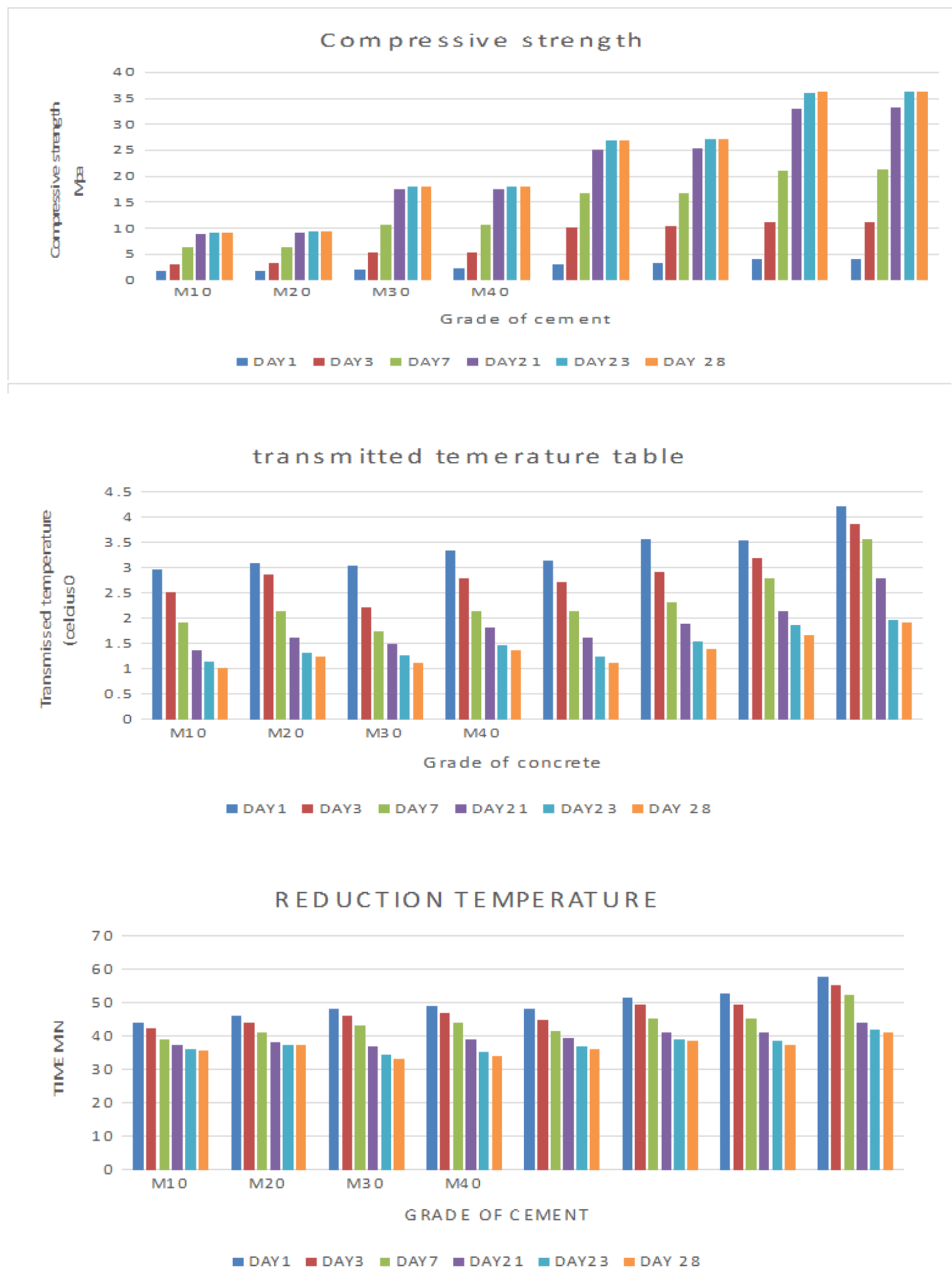


\section{Conclusions \& Recommendations}

From the fig (2) it can be observed that $\mathrm{M}_{20}$ grade concrete with safety match powder transmitted less temperature $\left(1.12^{0} \mathrm{c}\right)$ compared to the normal concrete $\left(1.3^{0} \mathrm{c}\right)$. Temperature transmittance capacity found more or less same for the entire grade. This clearly states that approximately $20 \%$ of heat transmitting property has decreased.

In Fig (3) shows time taken by each sample to cool down from $100^{0 \mathrm{c}}$ to $40^{\circ} \mathrm{c}$. Present study reveals that safety matches concrete cube takes very less time $37 \mathrm{~min} 46 \mathrm{sec}$ comparatively to the normal concrete $41 \mathrm{~min} 36 \mathrm{sec}$. That is $3 \mathrm{~min} 50 \mathrm{sec}$ faster. Hence it says the temperature liberated during chemical reaction may be less in the safety cubes.

Fig (1) shows. There is no considerable change in the compressive strength, in all the grades.

\section{Acknowledgements}

Special thanks for Hithesh Nagothu, Megha.R for helping me in completing this work successfully. And I also thank my parents, teachers, friends and all elders who supported me.

\section{References}

[1] Aubrey A. young, Tamaqua: offhqe slow match composition, 1931, 2.

[2] Farmer N.L, Reffell A, Kalin R, and M: Forensic analysis of wooden safety matches, 47(2), 2007, 1.

[3] IS10262-2009 page-2, clause 3.2.1.2, A-3 and B-3

[4] IS10262-2009 page-4 (APPEX-A)

[5] Shanmugapriya T, Uma R.N: Optimum of partial replacement of M-sand by Natural Sand in high performance concrete with silica fume, 2, 2012, 75.

[6] Ramazan Demirboga, Rumstem Gul: The effect of expanded perlitre aggregate, Silica fume and fly ash on the thermal conductivity of lightweight concrete: 33(5), 2003, 723-727.

\footnotetext{
*Corresponding author.

E-mail address: g.vishal1912@ gmail.com
} 